regulatory gene for the hexosamine formation might lead to increased biosynthesis of both glycosaminoglycans and gangliosides.

Basu, S., Kaufman, B. \& Roseman, S. (1968). J. biol. Chem. (in the Press).

Brady, R. O., Kanfer, J. N. \& Shapiro, D. (1965). Biochem. biophys. Res. Commun. 18, 221.

Jörgensen, L., Blackstad, Th. W., Harmark, W. \& Steen, J. A. (1964). Acta Neuropath. 4, 75.

Kaufman, B., Basu, S. \& Roseman, S. (1966). In Inborn Disorders of Sphingolipid Metabolism, p. 193. Ed. by Aronson, S. M. \& Volk, B. W. Oxford: Pergamon Press.

Klenk, E. (1942). Hoppe-Seyl. Z. 273, 76.

Kornfeld, S., Kornfeld, R., Neufeld, E. F. \& O'Brien, P. J. (1964). Proc. nat. Acad. Sci., Wash., 52, 371.

Leeden, R., Salsman, K., Gonatas, J. \& Taghavy, A. (1965). $J$. Neuropath. 24, 341.

Leibovitz, Z. \& Gatt, S. (1968). Biochim. biophys. Acta, 152, 136.

Okada, S. \& O'Brien, J. S. (1968). Science, 160, 1002.

Pilz, H., Sandhoff, K. \& Jatzkewitz, H. (1966). J. Neurochem. 13, 1273.

Svennerholm, L. (1966). In Inborn Disorders of Sphingolipid Metabolism, p. 169. Ed. by Aronson, S. M. \& Volk, B. W. Oxford: Pergamon Press.

\section{Wilson's Disease}

By J. M. WALShE. (Department of Investigative Medicine, University of Cambridge)

Wilson's disease: the problem. Also known as hepatolenticular degeneration, this is an hereditary metabolic disease associated with abnormal storage of copper in the liver, brain and kidneys. The pathological changes commonly found in these organs have been attributed to copper toxicity. The disease is inherited in an autosomal recessive fashion; a gene frequency of between 1/200 and 1/500 has been calculated. Symptoms may appear at any age from 6 to 40 years with a maximum incidence around 13 years. In children before puberty the illness usually appears as liver damage, and in some cases death may occur before the brain is involved. In older age groups the brain usually bears the brunt of the illness, the motor systems only being involved, even though copper is deposited in equally high concentrations in the sensory areas. Copper is also deposited in the kidneys, leading to renal-tubular defects, and in the cornea, giving rise to the typical pigmented rings. The disease, untreated, runs an almost invariably fatal course lasting for a few weeks to a few years at most.

Normal handling of copper. The normal intake of copper in the diet is between 2 and $4 \mathrm{mg}$. daily. As very little copper is excreted in the urine, balance must be maintained either by a barrier to absorption or by efficient biliary excretion. Studies using radioactive copper suggest that the latter is the mechanism normally employed, at least as far as ionic copper is concerned. Within $10 \mathrm{~min}$. of giving ${ }^{64} \mathrm{Cu}$ by mouth it can be detected in the plasma, and at about the same time surface counters will detect the appearance of radioactivity in the liver. In normal individuals between 60 and $80 \%$ of an injected dose of ${ }^{64} \mathrm{Cu}$ is present in the liver within $24 \mathrm{hr}$. The radioactivity in the blood shortly after oral or intravenous administration is present both in the cells and in the plasma, where it is bound mainly to albumin and also in small amounts of amino acids. Albumin-bound copper is given up to the liver, where some of it is incorporated into the serum protein caeruloplasmin before being returned to the circulation (Bearn \& Kunkel, 1954). Caeruloplasmin is an $\alpha$-globulin of mol.wt. 160000 (Kasper $\&$ Deutsch, 1963), each molecule containing 8 atoms of copper, which are present as cuprous-cupric pairs, the valence-changing ions forming a common acceptor site able to activate and reduce an oxygen molecule (Broman, 1964): the physiological substrate of this oxidase, if any, is unknown. Studies with caeruloplasmin labelled with ${ }^{64} \mathrm{Cu}$ have shown that there is no exchange in vivo, so that this is probably not a transport protein for the metal (Sternlieb, Morell, Tucker, Greene \& Scheinberg, 1961). Copper is carried to the tissues as either an albumin or an amino acid complex. It has been calculated that the normal adult male contains in his body about $100-150 \mathrm{mg}$. of copper, present as a series of copper proteins, hepatocuprein, cerebrocuprein, erythrocuprein and two with enzyme activity, tyrosinase and cytochrome $c$ oxidase. As the latter enzyme is present in most if not all cells of the body as the terminal step in the electrontransfer chain, copper is clearly essential for life.

Copper: the biochemical lesion. An experimental model of Wilson's disease in animals is not available, but it has been possible to show that the intracerebral injection of $\mathrm{Cu}^{2+}$ rapidly leads to convulsions and death. (Peters \& Walshe, 1966). Protection against convulsions was given by the synchronous injection of one of the thiols 2mercaptopropan-1-ol, thioctic acid or penicillamine. Studies in vitro showed that $\mathrm{Cu}^{2+}$ blocked pyruvate oxidation by mitochondria; more organized tissue breis or slices showed no significant inhibition of oxygen uptake at $\mathrm{Cu}^{2+}$ concentrations that induced convulsions in vivo. Further experiments showed that $\mathrm{Cu}^{2+}$ also blocked the $\mathrm{Mg}^{2+}-\mathrm{Na}^{+}-\mathrm{K}^{+}$-activated adenosine triphosphatase of pigeon brain microsomes, and it was suggested that this led to the onset of convulsions in vivo (Peters, Shorthouse \& Walshe, 1966).

Enzymic studies have not been possible on fresh brain from patients with Wilson's disease but it has long been known that copper concentrations are very high in brain, liver and kidney. In the plasma there is a deficiency of a caeruloplasmin, leading to a 
low concentration of copper, although albuminbound copper is present in marked excess; there is also a great increase in the rate of excretion of copper in the urine. Studies with ${ }^{64} \mathrm{Cu}$ have shown that as the disease progresses the liver steadily loses its ability to concentrate the metal until, in advanced cases, there is virtually no uptake of injected copper. Once treatment has been established and the patient adequately 'decoppered' the liver will regain its ability to concentrate the metal (Osborn \& Walshe, 1967). This has been interpreted as evidence that the binding sites for copper in the liver become progressively saturated until, late in the disease, the metal spills over and is deposited in other tissues, principally the brain and kidneys. The suggestion that the impaired hepatic uptake of copper is a consequence of non-specific liver damage unrelated to the genetic defect (Levi \& Williams, 1968), is based on inadequate data and failure to understand the natural history of the illness.

Treatment of Wilson's disease. If the theory that Wilson's disease is related to copper toxicity is correct then the mobilization of copper should result in reversal of the disease process. This has proved to be true so that the neurological, hepatic and renal lesions have all been shown to be reversible once negative copper balance has been established (Walshe, 1968). This is achieved by oral administration of penicillamine (Walshe, 1956), which renders copper available for filtration at the glomerulus. The copper so lost from the plasma is presumably replaced from the excess stored in the tissues; this can be demonstrated by observing the resorption of the copper deposits in the cornea. However, for treatment to be effective it is necessary to establish and maintain a negative copper balance over long periods of time. Of the large number of chemicals studied only penicillamine has so far proved able to do this.

Bearn, A. G. \& Kunkel, H. G. (1954). Proc. Soc. exp. Biol., N.Y., 85, 44.

Broman, L. (1964). Acta. Soc. med. upsalien. 69, suppl. 7.

Kasper, C. B. \& Deutsch, H. F. (1963). J. biol. Chem. 238, 2325.

Levi, A. J. \& Williams, H. S. (1968). Clin. Sci. 34, 379.

Osborn, S. B. \& Walshe, J. M. (1967). Lancet, i, 344.

Peters, R. A., Shorthouse, M. \& Walshe, J. M. (1966). Proc. Soc. Roy. B, 166, 285.

Peters, R. A. \& Walshe, J. M. (1966). Proc. Roy. Soc. B, 166, 273.

Sternlieb, I., Morell, A. G., Tucker, W. D., Greene, M. W. \&

Scheinberg, I. H. (1961). J. clin. Invest. 40, 1834.

Walshe, J. M. (1956). Amer. J. Med. 21, 487.

Walshe, J. M. (1968). Lancet, i, 775.
Inherited Abnormalities Affecting the Nervous System: Genetic and Psychiatric Aspects

By J. Stern and VALERIE CowIE. (Queen Mary's Hospital for Children, Carshalton, Surrey)

The biochemistry of a number of inborn errors of metabolism affecting the nervous system is well understood. However, even in so extensively studied a disorder as phenylketonuria, little is known about the mechanism by which brain function is disturbed (Menkes, 1967). In phenylketonuria the basic defect is largely extracerebral; the organ primarily involved is the liver. However, recent work suggests that phenylalanine may also be oxidized in the brain. Factors affecting the minor fraction of phenylalanine metabolized in the brain might well have a disproportionate effect on intellectual function (Pauling, 1968). A wide spectrum of psychiatric symptoms is found in untreated phenylketonurics, although these may be obscured by the severe impairment of the intelligence. The picture is further complicated by the genetic heterogeneity of the disease. Four alleles probably exist at the locus for phenylalanine 4-hydroxylase: the normal (wild type) allele, the silent typical allele for phenylketonuria and two further alleles, one of which gives rise to an enzyme susceptible to substrate inhibition and the other coding for an enzyme of low activity which is not, however, susceptible to substrate inhibition (Justice, O'Flynn \& Hsia, 1967; Woolf et al. 1968).

The interplay of genetic heterogeneity and variability in neuropsychiatric involvement is also found in histidinaemia. In most cases skin Lhistidine ammonia-lyase activity is absent. Woody, Snyder \& Harris (1965) found, however, that the enzyme was present in the skin of three siblings with the disease. In one family histidinaemia was found to be accompanied by alaninaemia (Auerbach, DiGeorge, Carpenter, Black \& Reusch, 1967). The majority of patients are mildly or moderately mentally retarded. The evidence for a specific speech defect is not convincing. There is no simple relation between the biochemistry and brain damage. Waisman (1967) studied four siblings with obesity, mental retardation and a degenerative brain disease. Three only of the children also had histidinaemia. Corner, Holton, Norman \& Williams (1968) found antenatal lesions in the brain of their patient. We have recently seen a 3-year-old girl with histidinaemia who is clinically perfectly well and has a I.Q. of 120.

Mental retardation is not always the most prominent neuropsychiatric symptom in inborn errors of metabolism. Thus a patient with hyperprolinaemia type 2, $\Delta^{1}$-pyrroline-5-carboxylic acid dehydrogenase deficiency, was only mildly retarded but had petit-mal epilepsy (Emery, Goldie \& Stern, 